\title{
COMPARATIVE STUDY OF DIFFERENT TYPES OF REPAIR MATERIALS IN FLEXURE
}

\author{
Laxmi $^{1}$, Shlok Singh ${ }^{2}$ \\ ${ }^{1}$ Assistant Prof, Department of Civil Engineering, ACSCE, Bengaluru, India \\ ${ }^{2}$ Assistant Prof, Department of Civil Engineering, ACSCE, Bengaluru, India \\ laxmiggandage@gmail.com, shloksingh87@gmail.com
}

\begin{abstract}
Repair and retrofitting of existing structures have become a major part of the construction activity. Some of the structures are damaged by load induced stresses, environmental effects etc. To avoid high cost of structural replacement and to maintain structural integrity different repair and rehabilitation techniques are required. The most common form of repair for a deteriorated concrete is through patching, thus increasing the design life of the structure. The objective of this experiment is to investigate the performance of different types of repair materials (mortar based and commercial repair products).Seven RCC beams of size $1500 \mathrm{~mm} \times 150 \mathrm{~mm} \times 200 \mathrm{~mm}$ were casted which include one concrete beam as control specimen (no repair)and six beams were casted by providing a wide mouthed trapezoidal notch at the bottom surface of the beam and all beams were cured for 28 days. Beams with notches were then patched with six selected types of repair materials in which one is repaired with normal concrete, three with mortar based repair materials and two with commercially available repair products and membrane cured for 28 days. All these beams were tested for flexural strength using two point loading in loading frame. Results were compared with control beam (no repair) and beam repaired with normal concrete. .
\end{abstract}

Keywords: Mix Design, Repair, Curing, Flexure, Failure.

\section{INTRODUCTION}

Repair and rehabilitation of concrete infrastructure is an important aspect of maintenance activities of a building structure, pavement, or a bridge in the world. The annual cost to the owners for repair, protection and strengthening is increasing day by day. Recent investigations of repairs to bridge decks and other structures have indicated an overwhelming incidence of premature failures resulting from a variety of factors. It is generally observed that a repair section in the concrete structure is mostly performed at the joints or in the tension area. Tension is induced in the concrete by bending of the structure due to loading or due to environmental conditions. Therefore, the flexural test method would be an appropriate method to study performance of different repair materials. Here it is aimed to study the flexural performance of different repair materials to strengthen or repair reinforced concrete beams. The performance of each repair material was assessed through flexural behaviour of different specimens.[1]

Seven RCC beams of size $1500 \mathrm{~mm} \times 150 \mathrm{~mm} \times 200 \mathrm{~mm}$ were casted. These specimens include one concrete beam as control specimen (no repair). Six beams were casted by providing a wide mouthed trapezoidal notch at the bottom surface of the beam and all beams were cured for 28 days. Beams with notches were then patched with six selected types of repair materials in which one is repaired with normal concrete, three with mortar based repair materials and two with commercially available repair products from BASF construction chemicals and membrane cured for 28 days. All these beams were tested for flexural strength using two point loading in loading frame. Results were compared with control beam (no repair) and beam repaired with normal concrete $\left(\mathrm{R}_{\mathrm{NC}}\right)$.

\section{MATERIALS}

The materials used in this investigation were cement, fine aggregate, coarse aggregate, conventional steel, water, super plasticizer (Conplast SP-430), silica fume, fly ash, commercially available repair products called EMACO S48C T, EMACO ${ }^{\text {TM }}$ S46 T and Roff concrete bond.[6,7]

\section{EXPERIMENTAL PROGRAM}

The experimental study consists of casting of seven RCC beams of dimensions $1500 \mathrm{~mm} \times 150 \mathrm{~mm} \times 200 \mathrm{~mm}$. Out of seven beams one beam was used as control specimen (no repair), and six beams were casted in such a way that a wide mouthed trapezoidal notch is created at the bottom surface of the beam which represents the damaged or deteriorated area that needs to be repaired using the repair materials. This notch was created at the middle third region of the beam. Beams with notches were patched with four selected types of repair materials using suitable bonding agent.

All beams have same flexural reinforcement of two \#10mm diameter deformed steel reinforcing bars as bottom reinforcement and two \#8mm diameter deformed steel reinforcing bars as top reinforcement. The flexural reinforcement is chosen to provide an under reinforced section with a flexural dominating behaviour. The shear reinforcement consists of \#6mm diameter deformed steel reinforcing bars as closed stirrups spaced at $150 \mathrm{~mm}$ along the beam longitudinal axis. [9] 


\subsection{Mix Design}

The mix proportion of M20 grade concrete designed as per IS $10262-1982$ is $0.52: 1: 1.596: 3.370$.[8]

\subsection{Casting}

Cube moulds of $70 \mathrm{~mm}$ were used for casting mortar cubes to determine the compressive strength of repair materials at 7days and 28days. Plywood mould of size $1500 \mathrm{~mm} \times 150 \mathrm{~mm} \times 200 \mathrm{~mm}$ were used for casting of beams. The internal surface of the mould is cleaned and a coat of oil is applied. The reinforcement cage prepared earlier is kept in the mould. To obtain the required clear cover mortar blocks of $25 \mathrm{~mm}$ thickness are kept at each end. The mould is filled with concrete in three layers with height of each layer equal to $1 / 3$ rd height of the mould and compacted uniformly with tamping rods. The top surface is smoothened and the mould is kept for drying to about 24 hours. Repair beams were casted with the same procedure as that of control beam expect that a trapezoidal notch is created in the flexure zone.

\subsection{Curing}

Pond curing method is adopted. All the test specimens are removed after 24 hours of casting from the moulds and placed in the tank for 28 days. After 28 days all the specimens are taken out from the tank and kept for air drying.

\subsection{Repair of Beams}

After 28 days of curing the beams are kept for air drying. Prior to patching of the repair materials the surface of the substrate concrete has to be prepared. The surface of the substrate concrete is chipped off using a hammer and chisel so that weak concrete is removed. Then all the loose particles, dust and debris are removed. The mixed material of bonding agent (Roff concrete bond) is evenly applied over the prepared and cleaned surface with a brush.[6]

\subsection{Testing Procedure}

\subsubsection{Compression Test}

Cube specimens are used for determining characteristic compressive strength. The load at which cube specimen fails is recorded. The compressive strength is calculated by dividing the ultimate load by cross sectional area of the specimen.

Cube compressive strength $=$ ultimate load $/ \mathrm{c} / \mathrm{s}$ Area

Table 1: Compressive strength of repair materials

\begin{tabular}{|l|l|l|}
\hline \multirow{2}{*}{ Repair material } & \multicolumn{2}{|c|}{ Curing period } \\
\cline { 2 - 3 } & 7 days & 28 days \\
\cline { 2 - 3 } & $\begin{array}{l}\text { Strength } \\
\left(\mathrm{N} / \mathrm{mm}^{2}\right)\end{array}$ & Strength $\left(\mathrm{N} / \mathrm{mm}^{2}\right)$ \\
\hline Normal concrete & 18 & 30 \\
\hline SF mortar & 34.218 & 47.221 \\
\hline FA mortar & 28.775 & 41.565 \\
\hline EMACO S48C T & 38.776 & 55.689 \\
\hline EMACO S46 T & 35.034 & 51.361 \\
\hline
\end{tabular}

\subsubsection{Testing of beams}

After the completion of air drying ( 24 hours) the specimen are cleaned to remove grit and dirt with the sand paper. White washing was done on all the sides of the beam and were kept ready for testing. White washing was done to facilitate easy detection of crack propagation. The testing is carried on structural loading frame. The loading reaction frame of $1000 \mathrm{KN}$ capacity consists of two movable steel Isections. These I-sections were adjusted to have an effective span of $1300 \mathrm{~mm}$. The beam to be tested is placed over these two supports. Steel rollers with grooved steel plates are placed between the beam and the I-section to provide two point loading system .By using plumb bob the centre line of the beam and the hydraulic jack were made to coincide with each other in order to prevent eccentric loading on beam. Proving ring of capacity $500 \mathrm{KN}$ was placed in its position to record the load values. Dial gauge was placed exactly beneath the mid-span of the beam to record deflection. The test set up is shown in the Fig 4.The load was applied at a regular interval of $0.725 \mathrm{KN}$. The load and corresponding deflection values are recorded and tested till the failure of the beam. The comparison of load versus deflection curve of control beam (C) with all repaired beams is shown in the Fig 1 and. 2

Table 2: Test results of all beams

\begin{tabular}{|c|c|c|c|c|}
\hline $\begin{array}{c}\text { Repair } \\
\text { material }\end{array}$ & $\begin{array}{c}\text { Material } \\
\text { Designa } \\
\text { tion }\end{array}$ & $\begin{array}{c}\text { Ultimate } \\
\text { Load, } \\
\mathrm{Pu} \\
(\mathrm{KN})\end{array}$ & $\begin{array}{c}\% \\
\text { decrease } \\
\text { in load } \\
\text { compare } \\
\text { d to } \\
\text { control } \\
\text { beam }\end{array}$ & $\begin{array}{c}\% \\
\text { increase } \\
\text { in load } \\
\text { compared } \\
\text { of normal } \\
\text { concrete }\end{array}$ \\
\hline Reference & Control & 39.995 & - & - \\
\hline $\mathrm{R}_{\mathrm{NC}}$ & $\begin{array}{c}\text { Normal } \\
\text { concrete }\end{array}$ & 34.195 & 14.5 & - \\
\hline $\mathrm{RG}_{1}$ & $\mathrm{R} 1$ & 34.92 & 12.69 & 2.12 \\
\cline { 2 - 5 } & $\mathrm{R} 2$ & 34.195 & 16.32 & 2.12 \\
\cline { 2 - 5 } & $\mathrm{R} 3$ & 35.645 & 10.88 & 4.24 \\
\hline $\mathrm{RG}_{2}$ & $\mathrm{R} 4$ & 37.095 & 7.25 & 8.48 \\
\cline { 2 - 5 } & $\mathrm{R} 5$ & 35.645 & 10.88 & 4.24 \\
\hline
\end{tabular}

Table -2: Test results of all beams (continued)

\begin{tabular}{|c|c|c|c|c|}
\hline $\begin{array}{c}\text { Repair material } \\
\text { Group }\end{array}$ & $\begin{array}{c}\text { Maximum } \\
\text { deflection } \\
(\mathrm{mm})\end{array}$ & $\begin{array}{c}\text { \% of } \\
\text { Control } \\
\text { beam }\end{array}$ & $\begin{array}{c}\mathrm{Pu} / \\
\mathrm{Pu}- \\
\text { control }\end{array}$ & $\begin{array}{c}\text { Appr } \\
\text { ox. } \\
\text { Cost } \\
(\mathrm{Rs})\end{array}$ \\
\hline Reference & 18.543 & - & 1.000 & - \\
\hline $\mathrm{R}_{\mathrm{NC}}$ & 19.812 & 106.85 & 0.855 & 45 \\
\cline { 2 - 5 } & 22.454 & 121.09 & 0.873 & 35 \\
\hline $\begin{array}{c}\mathrm{RG}_{1} \text { (Mortar } \\
\text { based repair } \\
\text { materials) }\end{array}$ & 18.085 & 97.5 & 0.855 & 30 \\
\cline { 2 - 5 } & 17.932 & 96.7 & 0.891 & 40 \\
\hline $\begin{array}{c}\mathrm{RG}_{2} \text { (Commerci } \\
\text { ally available } \\
\text { repair products }\end{array}$ & 22.606 & 121.91 & 0.927 & 500 \\
\cline { 2 - 5 } & 16.104 & 86.85 & 0.891 & 400 \\
\hline
\end{tabular}




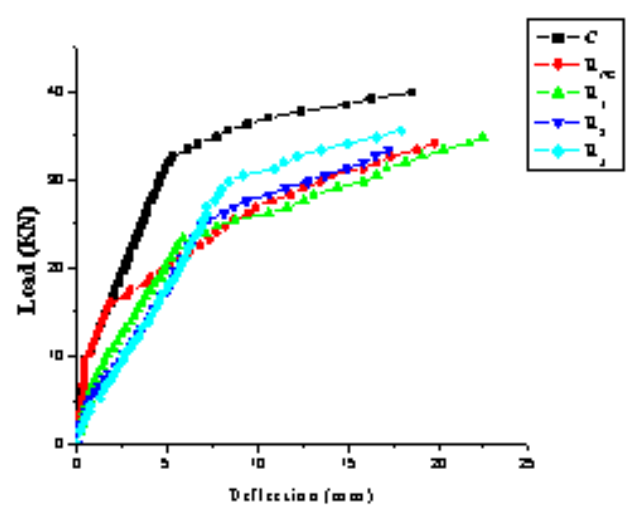

Fig 1. Comparison of load deflection curve of control beam and $\mathrm{R}_{\mathrm{NC}}$ with $\mathrm{R}_{1}, \mathrm{R}_{2} \& \mathrm{R}_{3}$

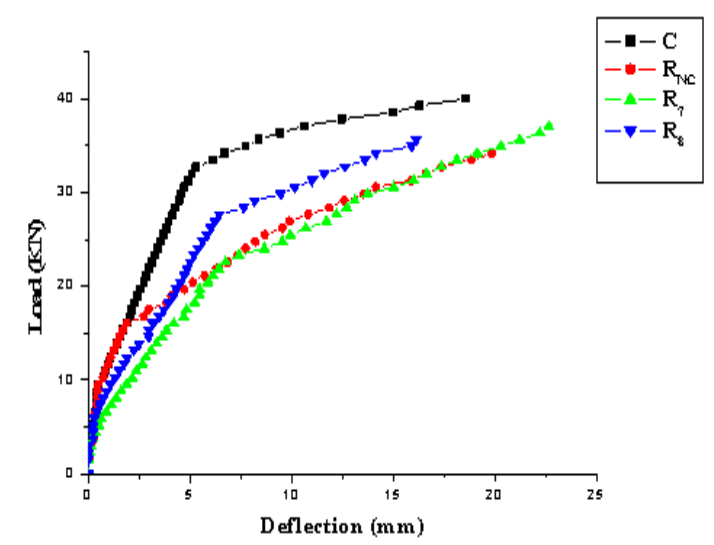

Fig 2. Comparison of load deflection curve of control beam and $\mathrm{R}_{\mathrm{NC}}$ with $\mathrm{R}_{4} \& \mathrm{R}_{5}$

\subsubsection{Failure modes of beams}

The failure mode of all the beams is shown in the Fig 3 to Fig 8

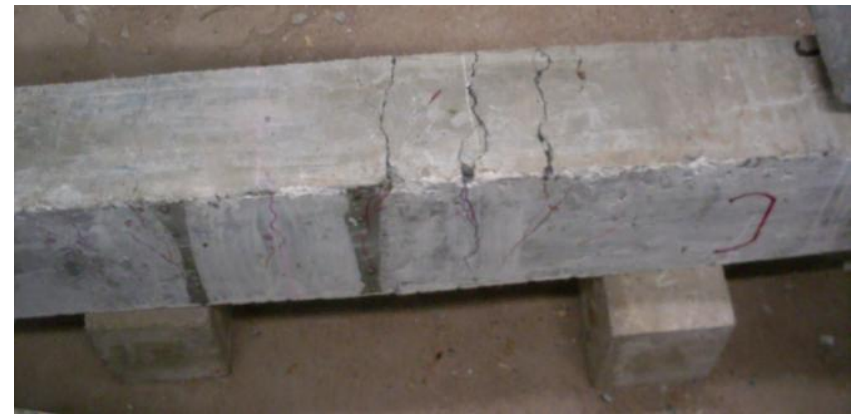

Fig 3. Control beam(C) failed in flexural crack

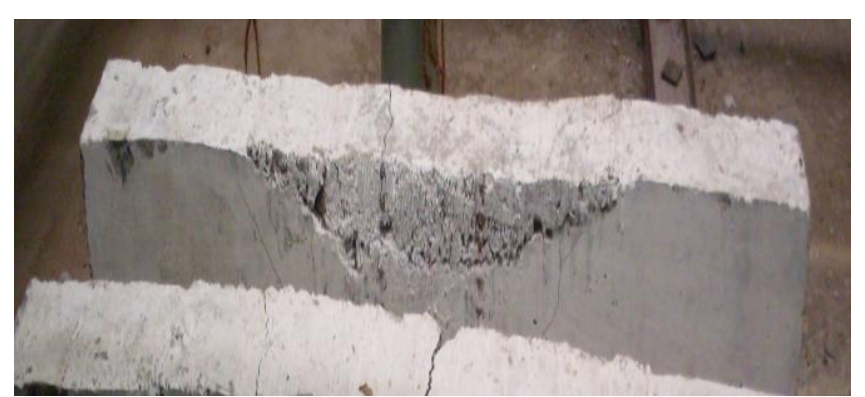

Fig 4. $R_{N C}$ beam (repaired with normal concrete) failed in flexural crack

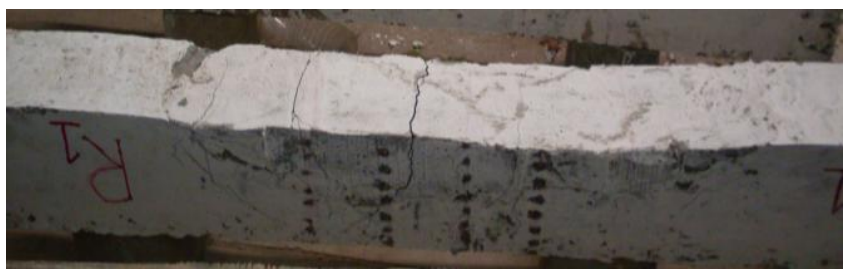

Fig 5: $\mathrm{R}_{1}$ beam (SF mort) failed due to debonding

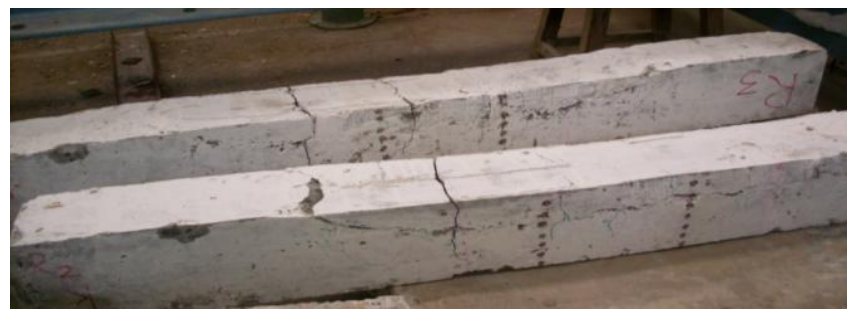

Fig 6: $\mathrm{R}_{2}$ beam (FA mort) failed due to debonding and $\mathrm{R} 3$ beam $((\mathrm{SF}+\mathrm{FA})$ mort $)$ failed in flexural crack

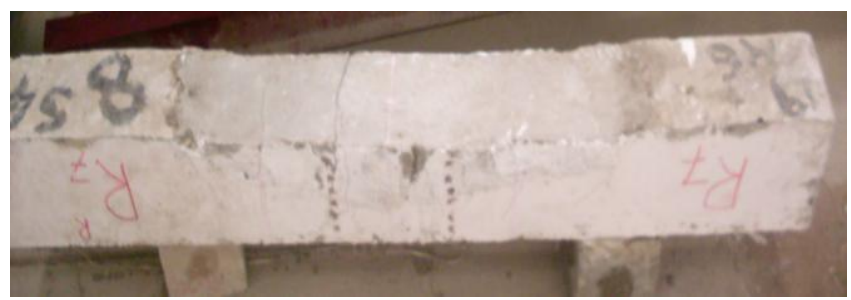

Fig 7. $\mathrm{R}_{4}$ (EMACO S48C T) failed in flexural crack

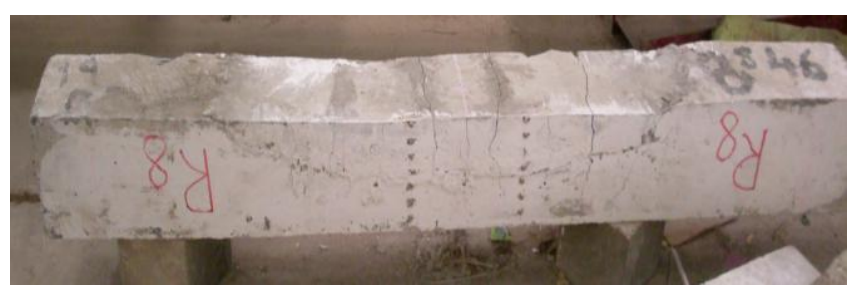

Fig 8. $\mathrm{R}_{5}(\mathrm{EMACO} \mathrm{S} 46 \mathrm{C} \mathrm{T})$ failed in flexural crack

\section{CONCLUSIONS}

1. The flexural strength of the beams repaired in tension with selected repair materials i.e. $R_{1}$ to $R_{5}$ increased in comparison with beam repaired with normal concrete $\left(\mathrm{R}_{\mathrm{NC}}\right)$. The increase in flexural strength is in the range of $2.12 \%$ to $4.24 \%$.

2. From the repair materials of same group $\mathrm{RG}_{1}$ (mortar based materials), it is seen that the beam repaired with $\mathrm{R} 3[\mathrm{SF}(10 \%)+\mathrm{FA}(20 \%)]$ materials exhibits better performance.

3. From the repair materials of same group $\mathrm{RG}_{2}$ (commercial based products), it is seen that the beam repaired with $\mathrm{R}_{5}$ (EMACOS48C $\mathrm{T}$ ) material exhibits better performance. The percentage of increase in flexural strength in comparison with the beam repaired with normal concrete $\left(\mathrm{R}_{\mathrm{NC}}\right)$ is $8.48 \%$ and decrease in strength is $7.25 \%$ in comparison with the flexural strength of control beam (C).

4. From the study of modes of failure of the beams it is observed that beams repaired with materials $R_{1}$ and $R_{2}$ failed due to bonding, $R_{3}$ failed in flexural cracks and $R_{4}$ and $R_{5}$ also failed in flexural crack. 
5. Among commercial repair products, EMACOS48 CT $\left(\mathrm{R}_{4}\right)$ shows better performance. The increase in flexural strength is $8.48 \%$ in comparison with capacity of control beam and the decrease in strength is $7.25 \%$ compared to beam repaired with normal concrete.

6. From this study it can be concluded that damaged parts subjected to tensile flexural stresses can be repaired using commercial repair material $\mathrm{R}_{5}$ by retaining the capacity of the beam nearer to its original capacity.

7. The costs of commercially available repair products are expensive compared to the cost of locally available repair materials.

\section{REFERENCES}

[1] ASTM. (2004a). Standard specification for packaged, dry, rapid-hardening cementitious materials for concrete repairs, ASTM C 928-00, Volume C 4.02, Philadelphia.

[2] Wells, A.J.; Stacrk, R.D. and Plyzois, D. "Getting Better Bond in Concrete Overlays." Concrete International, 21, No. 3 (March 1999), 49-52.

[3] Emmons, P.H. and Vaysburd, A.M. "System Concept in Design and Construction of Durable Concrete Repairs." Construction and Building Materials, 10, No. 1 (1996), 69-75.

[4] Nielson, N., M.,'Repair of concrete, types and methods", proceedings of the first conference, "Deterioration \& repair of reinforced concrete in the Arabian Gulf', BSE \& CIRIA, Vol I, October 1985,Bahrain, pp.117-125.

[5] CPWD Handbook on Repairs and Rehabilitation of RCC Buildings, Government of India, New Delhi 2002

[6] Indian Standard Specifications, "53 Grade Ordinary Portland Cement" IS: 12269-1987, Bureau of Indian Standards, New Delhi.

[7] Indian Standard Specifications, "Specifications for coarse and Fine Aggregate From Natural Source of Concrete" IS: 383-1970, Bureau of Indian Standards, New Delhi.

[8] Indian Standard, "Recommended Guidelines For Concrete Mix Design" IS: 10262-1982, Bureau of Indian Standards, New Delhi

[9] Indian Standard, "Plain And Reinforced Concrete Code of Practice" IS: 456:2000, Bureau of Indian Standards, New Delhi. 